Article

\title{
Arsenite as an Electron Donor for Anoxygenic Photosynthesis: Description of Three Strains of Ectothiorhodospira from Mono Lake, California and Big Soda Lake, Nevada
}

\author{
Shelley Hoeft McCann ${ }^{1, *}$, Alison Boren ${ }^{2}$, Jaime Hernandez-Maldonado ${ }^{2}$, \\ Brendon Stoneburner ${ }^{2}$, Chad W. Saltikov ${ }^{2}$, John F. Stolz ${ }^{3}$ and Ronald S. Oremland ${ }^{1, *}$ \\ U.S. Geological Survey, Menlo Park, CA 94025, USA \\ 2 Department of Microbiology and Environmental Toxicology, University of California, Santa Cruz, \\ CA 95064, USA; alisonboren@gmail.com (A.B.); jhernan4@ucsc.edu (J.H.-M.); bstonebu@ucsc.edu (B.S.); \\ saltikov@ucsc.edu (C.W.S.) \\ 3 Department of Biological Sciences, Duquesne University, Pittsburgh, PA 15282, USA; stolz@duq.edu \\ * Correspondence: smccann@usgs.gov (S.H.M.); roremlan@usgs.gov (R.S.O.); \\ Tel.: +1-650-329-4474 (S.H.M.); +1-650-329-4482 (R.S.O.)
}

Academic Editors: Rafael Montalvo-Rodríguez, Aharon Oren and Antonio Ventosa Received: 5 October 2016; Accepted: 21 December 2016; Published: 26 December 2016

\begin{abstract}
Three novel strains of photosynthetic bacteria from the family Ectothiorhodospiraceae were isolated from soda lakes of the Great Basin Desert, USA by employing arsenite (As(III)) as the sole electron donor in the enrichment/isolation process. Strain PHS-1 was previously isolated from a hot spring in Mono Lake, while strain MLW-1 was obtained from Mono Lake sediment, and strain BSL-9 was isolated from Big Soda Lake. Strains PHS-1, MLW-1, and BSL-9 were all capable of As(III)-dependent growth via anoxygenic photosynthesis and contained homologs of arxA, but displayed different phenotypes. Comparisons were made with three related species: Ectothiorhodospira shaposhnikovii DSM 2111, Ectothiorhodospira shaposhnikovii DSM 243 ${ }^{\mathrm{T}}$, and Halorhodospira halophila DSM 244. All three type cultures oxidized arsenite to arsenate but did not grow with As(III) as the sole electron donor. DNA-DNA hybridization indicated that strain PHS-1 belongs to the same species as Ect. shaposhnikovii DSM 2111 (81.1\% sequence similarity), distinct from Ect. shaposhnikovii DSM $243^{\mathrm{T}}$ (58.1\% sequence similarity). These results suggest that the capacity for light-driven As(III) oxidation is a common phenomenon among purple photosynthetic bacteria in soda lakes. However, the use of $\mathrm{As}(\mathrm{III})$ as a sole electron donor to sustain growth via anoxygenic photosynthesis is confined to novel isolates that were screened for by this selective cultivation criterion.
\end{abstract}

Keywords: arsenite; anoxygenic photosynthesis; soda lakes; arxA; Ectothiorhodospira

\section{Introduction}

The genus Ectothiorhodospira of the family Ectothiorhodospiraceae is composed of photosynthetic purple sulfur bacteria dependent on saline and alkaline growth conditions [1]. Isolates of this genus occur in marine environments as well as in the more chemically-extreme regimen of hypersaline and alkaline (soda) lakes [1]. They typically grow via anoxygenic photosynthesis using reduced sulfur compounds, hydrogen, or organic compounds (e.g., acetate, malate) as electron donors [2]. More recently, arsenite $(\mathrm{As}(\mathrm{III}))$ was also found to serve as an electron donor for anoxygenic photosynthesis in Mono Lake biomes: both in an Ectothiorhodospira-dominated enrichment culture cultivated from Mono Lake sediments [3] and in red biofilms located in the lake's hot springs [4]. Ectothiorhodospira strain PHS-1 was isolated from these biofilms and was shown to grow as a photoautotroph, using As(III) as its sole electron donor [4]. 
Both Mono Lake and Big Soda Lake waters contain abundant dissolved inorganic arsenic, 200 and $20 \mu \mathrm{M}$, respectively [5]. Mono Lake has been the more intensively studied of the two with respect to arsenotrophy [6] and has been found to support a breadth of arsenotrophic microbes. Arsenate-respiring bacteria in Mono Lake mediate the oxidation of organic matter [7] as well as the oxidation of inorganic electron donors like sulfide [8]. Diverse chemoautotrophic bacteria can oxidize arsenite (As(III)) to arsenate $(\mathrm{As}(\mathrm{V}))$ under aerobic or and anaerobic conditions, depending upon the species. The enzymes that support these pathways include a respiratory $A s(V)$ reductase (ArrAB-ArrABC) and an As(III) oxidase (AioBA; formerly referred to as AroAB, AoxAB or AsoAB). The arsenate reductase, ArrA, and arsenite oxidase, AioA, are members of the DMSO reductase family of molybdenum containing oxidoreductases and function catalytically to reduce arsenate or oxidize arsenite, respectively. ArrB and AioB are FeS subunits that participate in electron transfer to/from ArrA/AioA, respectively. ArrC is predicted to function as a quinol-oxidizing, membrane-anchoring subunit for ArrAB. Alkalilimnicola ehrlichii strain MLHE-1, isolated from Mono Lake water, grows chemo-autotrophically by coupling the oxidation of As(III) with the reduction of nitrate $[9,10]$. It lacks an arsenite oxidase (i.e., AioBA) and instead uses a different arsenite oxidase enzyme, ArxA (encoded by $\left.\operatorname{arx} B_{1} A B_{2} C\right)$, which more closely resembles ArrA than AioA, for oxidizing $\mathrm{As}(\mathrm{III})$ to $\mathrm{As}(\mathrm{V})$ [11]. ArxB and ArxC are predicted to function as FeS- and membrane-anchoring/quinone-reducing subunits, respectively. The $\operatorname{ar} x A$ gene is aligned more closely with $\operatorname{arr} A$ yet is comparatively distant from aio $A$, implying an evolutionary relationship with the former but not the latter [12]. Ectothiorhodospira strain PHS-1 also lacks the aio gene cluster but contains arx genes (including $\operatorname{ar} x A$ ) in a similar arrangement as MLHE-1 [13,14]. arxA genes were also found in the biofilms of the hot spring pools on Paoha Island [13]. Subsequent studies identified arxA-like sequences in Mono Lake, freshwater Hot Creek sediments, within the annotated metagenomes of several hot springs in Yellowstone National Park [14], and from sediments collected from Tukh Lake, an arsenic-rich soda lake located in Mongolia [15], indicating that $\operatorname{ar} x A$-type arsenite oxidases may be widespread in nature. Here we report the further characterization of strain PHS-1 and the isolation of two new strains of Ectothiorhodospira: strain MLW-1, isolated from shoreline sediments of Mono Lake and strain BSL-9, isolated from Big Soda Lake marsh water, all of which grow using As(III) as the sole electron donor that supports anoxygenic photosynthesis. In contrast, although closely related photosynthetic cultures from type collections could oxidize As(III), they were unable to sustain As(III)-dependent growth. Our results suggest that arsenotrophic growth among photosynthetic bacteria is more widespread than is currently recognized.

\section{Materials and Methods}

\subsection{Isolation and Growth}

Strain PHS-1 was isolated from red pigmented biofilms growing on rock surfaces in a hot pool $\left(\sim 45^{\circ} \mathrm{C}\right)$ located on Paoha Island in Mono Lake, CA $\left(37^{\circ} 59^{\prime} \mathrm{N} ; 119^{\circ} 01^{\prime} \mathrm{W}\right)$ and was maintained in an anaerobic liquid basal salts medium with As(III) as the electron donor, as previously described [4]. Strain MLW-1 was enriched from sediment collected from the littoral zone on the north shore of Mono Lake $\left(38^{\circ} 04^{\prime} \mathrm{N} ; 118^{\circ} 59^{\prime} \mathrm{W}\right)$. The enrichment was maintained in an artificial medium containing the following (g/L): $\mathrm{NaCl}(60),\left(\mathrm{NH}_{4}\right)_{2} \mathrm{SO}_{4}(0.1), \mathrm{KH}_{2} \mathrm{PO}_{4}(0.08), \mathrm{K}_{2} \mathrm{HPO}_{4}(0.15), \mathrm{MgSO}_{4} \cdot 7 \mathrm{H}_{2} \mathrm{O}(0.025)$, $\mathrm{Na}_{2} \mathrm{CO}_{3}$ (10.6), $\mathrm{NaHCO}_{3}$ (4.2), $\mathrm{Na}_{2} \mathrm{WO}_{4}$ (0.00001), and Widdel et al.'s [16] trace elements solution $(5 \mathrm{~mL})$. The $\mathrm{pH}$ was adjusted to 9.8 , bubbled with $\mathrm{O}_{2}$-free $\mathrm{N}_{2}$ for $30 \mathrm{~min}$ and $9 \mathrm{~mL}$ of medium was dispensed into anoxic, $\mathrm{N}_{2}$-flushed Balch-type tubes $(\sim 25 \mathrm{~mL})$, which were then crimp sealed and sterilized by autoclaving $\left(121^{\circ} \mathrm{C}, 250 \mathrm{kPa}\right.$ for $\left.60 \mathrm{~min}\right)$. The medium was amended with $2 \mathrm{mM} \mathrm{As}(\mathrm{III})$, $0.1 \mathrm{mM}$ sulfide and $10 \mathrm{~mL} / \mathrm{L}$ of a vitamin solution [17], all from sterile anaerobic stock solutions and incubated in the light ( 25 watt bulb; $1000 \mathrm{lux}$ ) at $28^{\circ} \mathrm{C}$. After several transfers in liquid medium, the enrichment culture was streaked onto $1.5 \%$ agar medium contained in agar bottle plates [18], sealed under $\mathrm{N}_{2}$, and incubated in the light at $28^{\circ} \mathrm{C}$. All manipulations were done using sterile technique in an anaerobic glove box. Pink colonies were noted after about 7-14 days and were picked and 
re-inoculated into the original sterile liquid medium. The purity of the culture was determined by morphological uniformity and by no ambiguous $16 \mathrm{~S}$ rRNA sequences. MLW- 1 was maintained with $2 \mathrm{mM}$ As(III) as the electron donor, $0.1 \mathrm{mM}$ sulfide as a reducing agent and incubated at $28^{\circ} \mathrm{C}$ statically in the light.

Strain BSL-9 was isolated in 2011 from water collected in the shallow swamp region of Big Soda Lake $\left(39^{\circ} 31^{\prime} \mathrm{N}, 118^{\circ} 53^{\prime} \mathrm{W}\right)$ and the enrichment was performed as described for strain MLW-1 using the following artificial medium: $\left(\mathrm{g} / \mathrm{L}^{-1}\right): \mathrm{NaCl}(25.0), \mathrm{KH}_{2} \mathrm{PO}_{4}(0.24), \mathrm{K}_{2} \mathrm{HPO}_{4}(0.3)\left(\mathrm{NH}_{4}\right)_{2} \mathrm{SO}_{4}(0.23)$, $\mathrm{MgSO}_{4}(0.12), \mathrm{Na}_{2} \mathrm{CO}_{3}(5.3), \mathrm{NaHCO}_{3}(2.1)$, yeast extract (0.02), vitamin B12 (0.0002), SL10 trace element solution $(1 \mathrm{~mL})$ [19], vitamin $\operatorname{mix}(10 \mathrm{~mL})$ [20], and adjusted to $\mathrm{pH}$ 9.7. Once established, BSL-9 was typically grown in the light ( 2000 lux) at $30^{\circ} \mathrm{C}$ with $2 \mathrm{mM} \mathrm{As(III)}$ as the electron donor.

Ectothiorhodospira shaposhnikovii (DSM 2111) and Ectothiorhodospira shaposhnikovii (DSM 243 ${ }^{\mathrm{T}}$ ) were maintained in ATCC medium \#1448 at pH 9 with $10 \mathrm{mM}$ acetate and $2 \mathrm{mM}$ sulfide as electron donors. Halorhodospira halophila (DSM 244) was maintained in DSM medium \#253 at pH 8.5 with $6 \mathrm{mM}$ succinate and $4 \mathrm{mM}$ sulfide as electron donors. All three of these strains were incubated in the light $(25 \mathrm{~W}$ bulb, $\sim 1000$ lux) at $28^{\circ} \mathrm{C}$.

Growth of cultures was monitored by optical density at $680 \mathrm{~nm}(600 \mathrm{~nm}$ for strain BSL-9) by spectrophotometry. All growth experiments were conducted in $25-\mathrm{mL}$ Balch tubes filled with $9 \mathrm{~mL}$ of anoxic medium and $\mathrm{N}_{2}$ headspace and inoculated with $1 \mathrm{~mL}$ of liquid culture. Tubes were illuminated by a $25 \mathrm{~W}$ tungsten light bulb and incubated statically at $28^{\circ} \mathrm{C}$. Growth of strain MLW-1 was tested with $2 \mathrm{mM} \mathrm{As(III)} \mathrm{(initial} \mathrm{concentration)} \mathrm{as} \mathrm{the} \mathrm{electron} \mathrm{donor} \mathrm{and} 0.1 \mathrm{mM}$ sulfide as a reducing agent. During incubation, arsenic speciation was monitored and, as As(III) was removed, it was replaced with further injections of $2 \mathrm{mM} \mathrm{As(III)} \mathrm{so} \mathrm{as} \mathrm{to} \mathrm{avoid} \mathrm{the} \mathrm{overt} \mathrm{growth-preventing} \mathrm{toxicity} \mathrm{of} \mathrm{initially}$ adding too much arsenite (e.g., 5-10 mM) [4]. Strain BSL-9 was grown in BSM with an initial arsenite concentration of $0.5 \mathrm{mM}$ at approximately 2000 lux. Growth was determined from the absorbance at $600 \mathrm{~nm}$. As growth increased, several subsequent $\sim 0.5 \mathrm{mM}$ arsenite additions were made to cultures as is outlined above for strain MLW-1.

To examine whether PHS-1 and MLW-1 could use electron donors other than As(III) for growth, transfers of $1.0 \mathrm{~mL}$ inoculum were made into crimp-sealed Balch tubes containing $9 \mathrm{~mL}$ of medium. Electron donors were added from sterile anoxic stock solutions to yield the final concentrations given in Table 1, while controls lacked electron donors. Growth was monitored by optical density at $680 \mathrm{~nm}$. If growth occurred, the culture was transferred twice sequentially into the same medium for confirmation of sustained growth. Due to PHS-1's very high $16 \mathrm{~S}$ rRNA sequence similarity $(>97 \%)$ to Ect. shaposhnikovii DSM 2111 and Ect. shaposhnikovii DSM 243 ${ }^{\mathrm{T}}$, these organisms were tested alongside strain PHS-1 and MLW-1. Ect. shaposhnikovii DSM 2111 was tested for growth on all electron donors listed in Table 1, while Ect. shaposhnikovii DSM 243 was tested only with the following electron donors: lactate, acetate, and butyrate. For strain BSL-9, a liquid culture was first grown in BSM with $10 \mathrm{mM}$ malate ( $\mathrm{pH}$ 9.7) for three days and diluted $1 / 10$ in blank medium. The diluted culture was inoculated $(300 \mu \mathrm{L})$ into $10 \mathrm{~mL}$ of anaerobic medium containing the following organic acids as electron donors $(10 \mathrm{mM})$ : malate, acetate, propionate, pyruvate, succinate, fumarate, and lactate, followed by incubation at $30{ }^{\circ} \mathrm{C}$. Growth $\left(\mathrm{OD}_{600 \mathrm{~nm}}\right)$ was monitored daily. No growth was observed in the absence of any added organic acid substrates.

The ability of the three strains to grow over a range of salinity, $\mathrm{pH}$ and temperature was examined by growing the organisms with $10 \mathrm{mM}$ acetate in the light. Salinities were varied by altering the concentration of $\mathrm{NaCl}$ in the media: $(0-175 \mathrm{~g} / \mathrm{L}$; strain MLW-1; 0-80 g/L strain PHS-1; 0-100 $\mathrm{g} / \mathrm{L}$ strain BSL-9. The $\mathrm{pH}$ range was tested using the media described above, buffered with $\mathrm{Na}_{2} \mathrm{CO}_{3} / \mathrm{NaHCO}_{3}$ for $\mathrm{pH}$ range 8.5-12 and adjusted with concentrated $\mathrm{HCl}$ or $6 \mathrm{~N} \mathrm{NaOH}$. For $\mathrm{pH}$ range 6.5-8.5, the buffer was HEPES $/ \mathrm{Na}_{2} \mathrm{CO}_{3}$ (PHS-1: $35.7 \mathrm{~g} / \mathrm{L}$ HEPES + 5.3 g/L Na $2 \mathrm{CO}_{3}$; MLW-1: $23.8 \mathrm{~g} / \mathrm{L}$ HEPES $\left.+10.6 \mathrm{~g} / \mathrm{L} \mathrm{Na}_{2} \mathrm{CO}_{3}\right)$. Specific growth rates $(\mu)$ were determined by a least-squares linear fit to the following formula: $\mu=\ln \left(\mathrm{N} / \mathrm{N}_{0}\right) / \mathrm{t}$, where $\mathrm{N}_{0}$ and $\mathrm{N}$ are $\mathrm{OD}_{680 \mathrm{~nm}}$ values for the time interval displaying exponential growth. 
Table 1. Phototrophic growth of Ectothiorhodospira strains on a diversity of electron donors. All organic/inorganic sources were at $5 \mathrm{mM}$ unless otherwise noted. Growth indices $\left(\mathrm{OD}_{680}\right)$ are as follows: +, growth; -, no growth; ND, not determined.

\begin{tabular}{|c|c|c|c|c|c|c|}
\hline & MLW-1 & PHS-1 & BSL-9 & $\begin{array}{l}\text { Ect. shaposhnikovii } \\
\text { (DSM 2111) }\end{array}$ & $\begin{array}{l}\text { Ect. shaposhnikovii } \\
\text { (DSM 243) Type Strain }\end{array}$ & $\begin{array}{l}\text { Halorhodospira } \\
\text { halophila }\end{array}$ \\
\hline Arsenite (2 mM) & + & + & + & - & - & - \\
\hline Sulfide & + & + & + & + & + & $+b$ \\
\hline Thiosulfate & + & + & + & + & $+{ }^{a}$ & $+b$ \\
\hline Sulfur & + & + & + & + & $+{ }^{a}$ & $+{ }^{b}$ \\
\hline Hydrogen & - & - & ND & - & $++^{a}$ & ND \\
\hline Acetate & + & + & + & + & + & $++^{b}$ \\
\hline Lactate & + & + & + & + & + & ND \\
\hline Propionate & + & + & + & + & $+{ }^{a}$ & ND \\
\hline Fructose & + & - & ND & + & $+{ }^{a}$ & ND \\
\hline Glucose & + & - & ND & - & ND & ND \\
\hline Succinate & + & + & + & + & $+{ }^{a}$ & $+{ }^{b}$ \\
\hline Malate & + & + & + & + & $+{ }^{a}$ & ND \\
\hline Pyruvate & + & + & + & + & $++^{a}$ & ND \\
\hline Butyrate & - & - & ND & + & - & ND \\
\hline
\end{tabular}

\subsection{Sequencing and Phylogenetic Analysis}

The 16S rRNA gene sequencing for PHS-1 was performed as described in Kulp et al. [4]. Genomic DNA of strains MLW-1 and BSL-9 were extracted using the Qiagen DNeasy Blood and Tissue Kit (Qiagen, Hilden, Germany). The following PCR conditions were used to amplify the 16S rRNA gene: $25 \mu \mathrm{L} 2 \times$ Taq mixture (Promega), $5 \mu \mathrm{L} 10 \times$ reaction buffer, and $5 \mu \mathrm{L}$ each of $2 \mu \mathrm{M}$ forward and reverse primer (8F, 5'-GAGTTTGATCCTGGCTCAG-3' and 1492R, 5'-GGTTACCTTGTTACGACTT-3'). The PCR products were cloned using the Invitrogen TA-TOPO cloning kit according to the manufacturer's instructions. Clones were screened for correctly sized inserts ( 1500 bp). Sequencing was done on replicate clones by Sequetech DNA Sequencing Service (Mountain View, CA, USA) with forward (M13F) and reverse (M13R) vector-specific primer. For each organism, the forward and reverse sequencing reads were manually inspected and assembled into a contiguous sequence based on the overlapping regions resulting in a nearly complete $16 \mathrm{~S}$ rRNA gene.

Taxa inferences were done using NCBI BLAST and the partial 16S rRNA genes for MLW-1, BSL-9, and PHS-1. Additional 16S rRNA gene sequences of closely related Ectothiorhodospira strains were obtained from NCBI. The sequences were aligned using CLUSTAL $X$ and a neighbor-joining tree was constructed using PAUP* 4.0b [22].

DNA-DNA hybridization assays of strain PHS-1 against Ect. shaposhnikovii DSM 2111 and Ect. shaposhnikovii DSM $243^{\mathrm{T}}$ were conducted at the Deutsche Sammlung von Mikrooganismen und Zellkulturen (DSMZ). Cells were disrupted by using a Constant Systems TS 0.75 KW (IUL Instruments, Königswinter, Germany) and the DNA in the crude lysate was purified by chromatography on hydroxyapatite as described by Cashion et al. [23]. DNA-DNA hybridization was carried out as described by De Ley et al. [24] under consideration of the modifications described by Huss et al. [25] using a model Cary 100 Bio UV/VIS-spectrophotometer (Agilent, Santa Clara, CA, USA) equipped with a Peltier-thermostatted $6 \times 6$ multi-cell changer and a temperature controller with in situ temperature probe (Varian). The G + C base composition of strain MLW-1 was determined by HPLC at the DSMZ.

\subsection{Detection of arxA and aioA}

Each strain was screened by PCR for arxA using primers BSL9arxA295f (5'-GGCGCCTATTTCCTGTATGA-3') and BSL9arxA912r (5'-GGCAAAGTCACCCACAAACT-3'). The arsenite oxidase gene, aioA was detected using primers reported in Sultana, et al. [26]: AOX-F-A2: 5'-TGCATCGTCGGCTGYGGNTAY-3' and AOX-R-E2: 5'-TTCGGAGTTATAGGCCGGNCKRTTRTG-3'. The $\operatorname{arxA}$ PCR conditions were: $200 \mathrm{nM}$ of each primer, $2 \times$ Taq mixture from Promega, and template 
DNA ( 10-50 ng). The following thermocycle profile was used: an initial denaturation at $95^{\circ} \mathrm{C}$ for $5 \mathrm{~min}$, followed by 30 cycles of $95^{\circ} \mathrm{C}$ for $30 \mathrm{~s}, 55^{\circ} \mathrm{C}$ primer annealing for $30 \mathrm{~s}, 72^{\circ} \mathrm{C}$ extension for $1 \mathrm{~min}$, followed by a final extension at $72{ }^{\circ} \mathrm{C}$ for $5 \mathrm{~min}$. The aio $A$ (previously referred to as aoxB) PCR conditions were similar to $\operatorname{arx} A$ however a $57^{\circ} \mathrm{C}$ primer annealing temperature was used. The presence of $550 \mathrm{bp}$ or $670 \mathrm{bp}$ bands on an agarose gel was indicative of successful amplification of $\operatorname{arx} A$ and aio $A$, respectively. The PCR products were cloned using the Invitrogen TA-TOPO cloning kit and sequenced using the Sanger method. BLAST analysis of the partial $\operatorname{ar} x A$ and aio $A$ sequences were done using NCBI databases confirming the initial identity of the amplified arsenite oxidase sequences. The PHS-1 genome sequence is reported in Zargar et al. [14] and is available through NCBI accession number PRJNA68693. The BSL-9 genome sequence was completed using PacBio sequencing service at UC Davis, CA. High molecular weight DNA was prepared from a freshly grown culture initiated from a single colony that was streak plated on an agar medium containing acetate and arsenite. DNA was extracted using the Qiagen Genomic Tip 500-G (Qiagen, Germantown, MD, USA) according to the manufacturer's instructions. The genome assembly and annotation are described in Hernandez-Maldonado et al. [27] and available through the NCBI BioProject and BioSample accession numbers PRJNA232800 and SAMN03795182, respectively.

\subsection{Electron Microscopy}

Samples for scanning electron microscopy (SEM) were prepared according to Smith et al. [28]. For transmission electron microscopy, cells were fixed by addition of glutaraldehyde directly to the medium (liquid cultures) for a final concentration of $2.5 \%$. Samples were post-fixed with $1 \%$ osmium tetroxide in $0.5 \mathrm{M}$ sodium acetate, en bloc stained with uranyl acetate (1\% in deionized water), dehydrated in an ethanol series and propylene oxide, followed by infiltration with Spurr's embedding medium as described in Switzer Blum et al. [29]. Samples were observed on a JEOL 100CX or 1210 transmission electron microscope (JEOL USA, Peabody, MA, USA) at $60 \mathrm{kV}$. Digital images were minimally processed for brightness and contrast.

\subsection{Analytical Methods}

Arsenic speciation and concentration and succinate concentration were determined by highperformance liquid chromatography (HPLC) using a Thermo Scientific Ultimate 3000 chromatograph (Thermofisher, Sunnyvale, CA, USA) with a UV-VIS detector (RS variable wavelength detector) set at $190 \mathrm{~nm}$. Arsenate and arsenite were separated using two columns in series (Bio-Rad Aminex HPX-87H and Hamilton PRP X300) with a $0.016 \mathrm{~N} \mathrm{H}_{2} \mathrm{SO}_{4}$ eluent at a flow rate of $0.6 \mathrm{~mL} / \mathrm{min}$. Retention times for arsenate and arsenite were 11.9 and $16.6 \mathrm{~min}$, respectively. The retention time for succinate was $32 \mathrm{~min}$. Sulfide was determined spectrophotometrically [30].

\section{Results}

\subsection{Growth Experiments}

Ectothiorhodospira strain PHS-1 was previously shown to achieve light-dependent anaerobic growth by oxidizing As(III) to As(V). A series of pulsed additions of $\sim 1-2 \mathrm{mM}$ As(III) was made over time so as to avoid an initial inhibitory effect of this toxicant when applied at higher concentrations [4]. Similarly, strains MLW-1 and BSL-9 both grew as photoautotrophs by oxidizing pulsed additions of $\mathrm{As}(\mathrm{III})$ to $\mathrm{As}(\mathrm{V})$ under anaerobic conditions (Figure 1A,B). Growth of both BSL-9 and MLW-1 did not occur without As(III) (Figure 1A,B).

Three closely related species from culture collections were tested for their ability to grow by oxidizing As(III) in the light. Ectothiorhodospira shaposhnikovii (DSM $243^{\mathrm{T}}$ ) oxidized As(III) to As(V) in the light under anaerobic conditions, but growth occurred only when abundant sulfide ( $2 \mathrm{mM})$ was present (Figure 2A) and growth was slightly greater in cultures given As(III) plus sulfide than in cultures grown only with $2 \mathrm{mM}$ sulfide (Figure 2B). Growth did not occur in this strain when As(III) was 
provided as the sole electron donor (Figure S1). Ectothiorhodospira shaposhnikovii (DSM 2111) oxidized $\mathrm{As}(\mathrm{III})$ to $\mathrm{As}(\mathrm{V})$ in the light under anaerobic conditions when $2 \mathrm{mM}$ sulfide was present (Figure 2C), but As(III) did not notably enhance growth (Figure 2D). As with Ect. shaposhnikovii DSM 243, growth did not occur when As(III) was provided as the sole electron donor (Figure S1). Halorhodospira halophila (DSM 244) oxidized As(III) to $\mathrm{As}(\mathrm{V})$ in the light under anaerobic conditions in the presence of succinate plus sulfide ( $6 \mathrm{mM}$ and $0.5 \mathrm{mM}$, respectively)(Figure 2E). Growth of H. halophila was greater in the As(III) plus succinate/sulfide condition when compared with the succinate/sulfide that lacked As(III) (Figure 2F). Growth did not occur when As(III) was the sole electron donor (Figure S2).

Strains MLW-1, PHS-1, and BSL-9 were tested for photosynthetic growth on a variety of other electron donors besides As(III). Strains MLW-1 and PHS-1 were able to use sulfide, thiosulfate, and sulfur, but not hydrogen, while strain BSL-9 grew on sulfide, thiosulfate, and sulfur (hydrogen was not tested). Photo-heterotrophic growth was observed in MLW-1 and PHS-1 with acetate, lactate, propionate, succinate, malate, and pyruvate but not with butyrate. BSL-9 also grew on these organic acids in addition to fumarate. Strain MLW-1 also grew with glucose and fructose, while strain PHS-1 did not (Table 1).
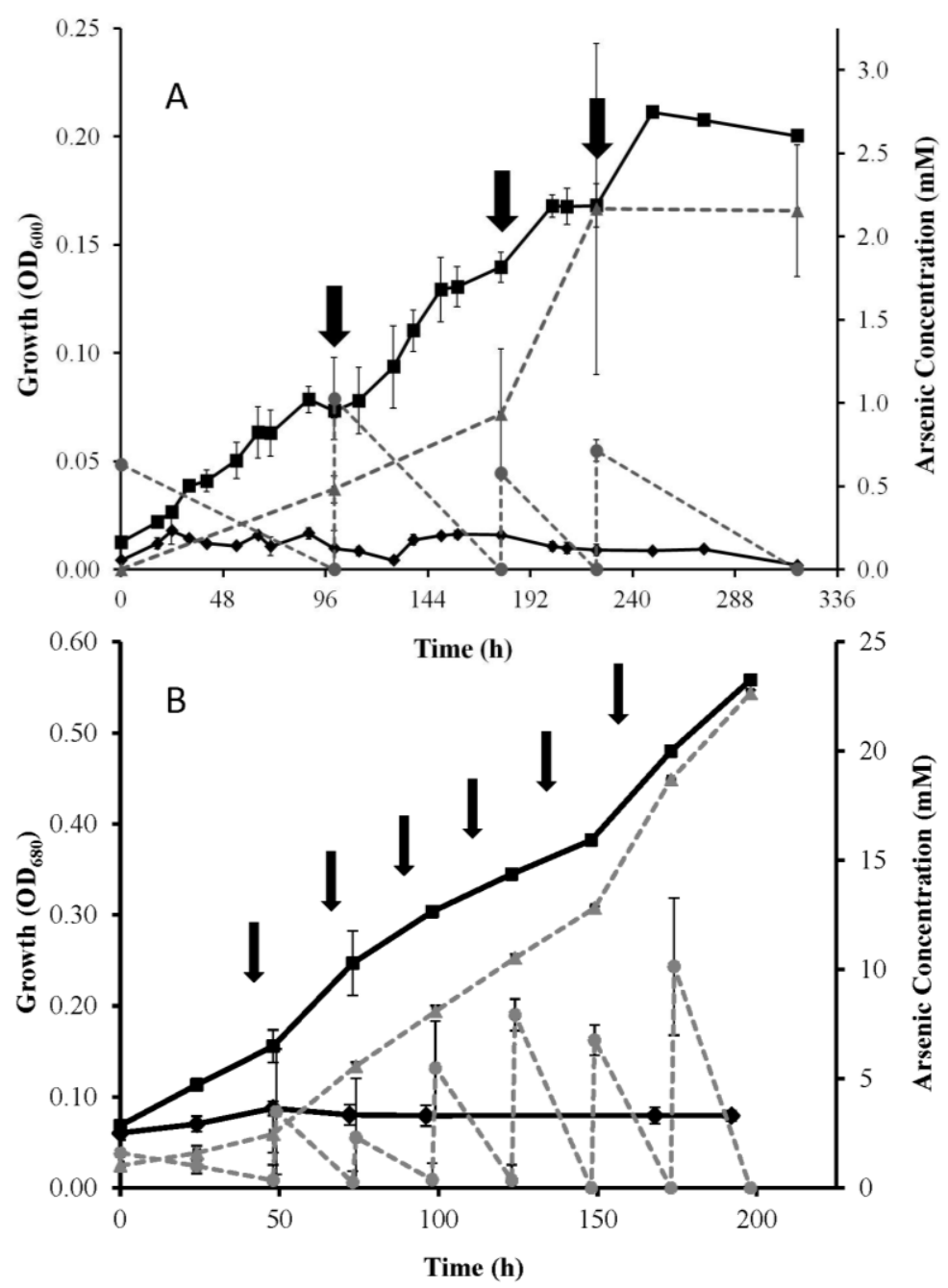

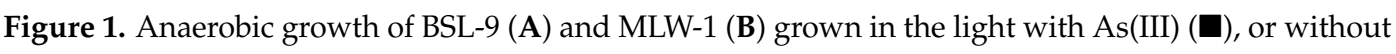

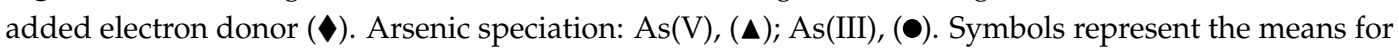
three separate cultures, and error bars indicate \pm standard deviation. Arrows indicate when additional As(III) was added to the cultures. 

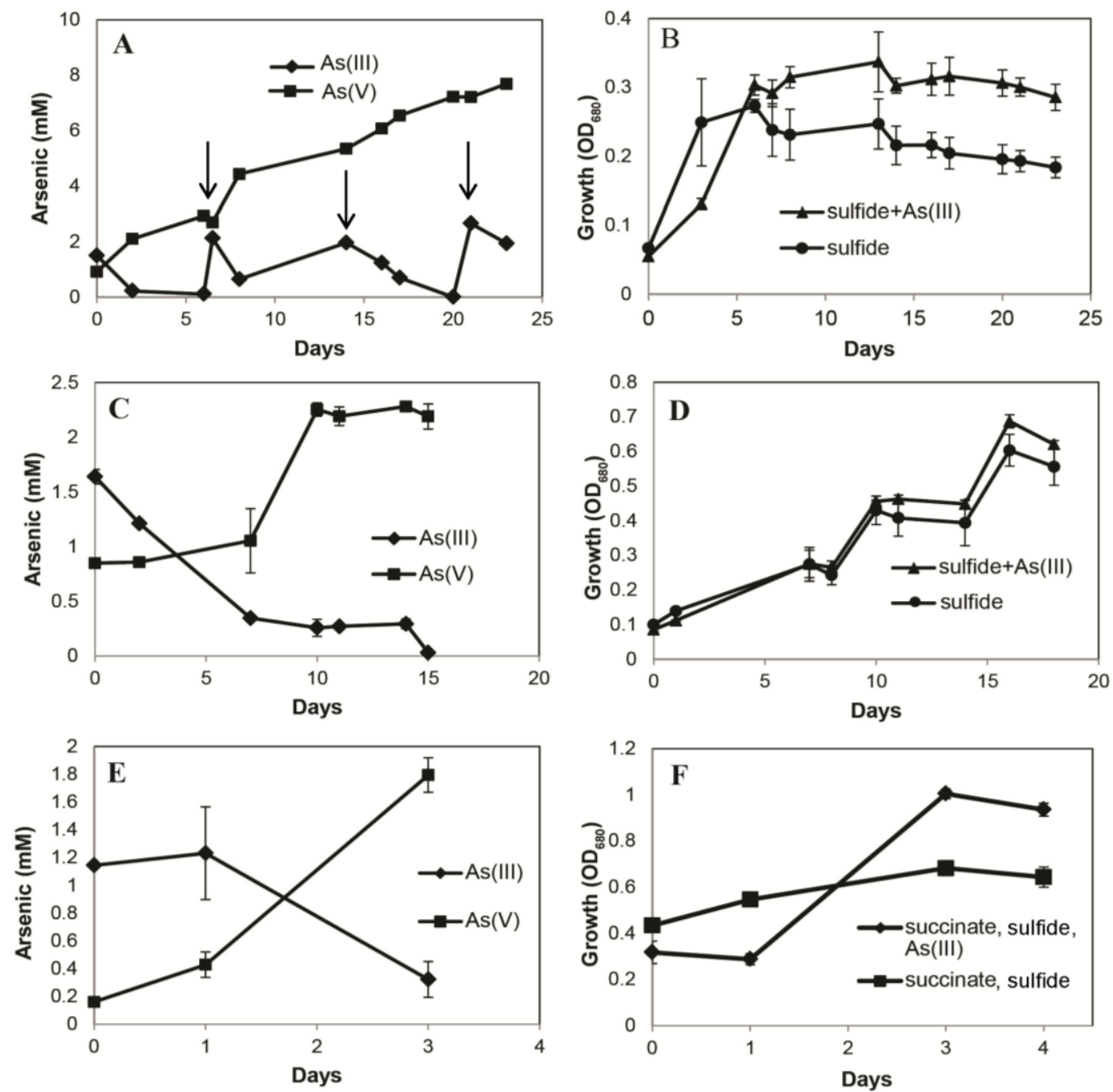

Figure 2. Phototrophic arsenite oxidation (left column) and growth (right column) in three closely related photosynthetic bacteria from culture collections. (A) As(III) oxidation to As(V) by Ectothiorhodospira shaposhnikovii DMS $243^{\mathrm{T}}$ with added sulfide $(2 \mathrm{mM})$. Arrows indicate additions of $2 \mathrm{mM}$ As(III); (B) Growth of Ect. shaposhnikovii DSM $243^{\mathrm{T}}$ in the light with As(III) + sulfide and sulfide alone; (C) As(III) oxidation to As(V) by Ectothiorhodospira shaposhnikovii DSM 2111 with added sulfide (2 mM); (D) Growth of Ect. shaposhnikovii DSM 2111 in the light with As(III) + sulfide and with sulfide alone; (E) As(III) oxidation to As(V) by Halorhodospira halophila with added sulfide (2 $\mathrm{mM})$ and succinate $(6 \mathrm{mM})$; (F) Growth of H. halophila in the light with As(III) + succinate + sulfide compared to succinate + sulfide. Symbols represent the mean of three cultures, and bars indicate \pm SD.

Optimum growth of strains MLW-1, PHS-1, and BSL-9 (Figure 3) occurred at $27{ }^{\circ} \mathrm{C}, 43^{\circ} \mathrm{C}$, and $35^{\circ} \mathrm{C}$, respectively. The three strains were alkaliphilic. Strain MLW-1 exhibited a maximum growth rate in the $\mathrm{pH}$ range of 7.9-9.8, PHS-1 grew best at $\mathrm{pH}$ range 8.7-9.3, and BSL-9 grew best over a $\mathrm{pH}$ range of 8.0-9.5. Growth of strain MLW-1 occurred over a salinity range of $15-165 \mathrm{~g} \cdot \mathrm{L}^{-1}$, with the highest growth rates occurring at $15-115 \mathrm{~g} \cdot \mathrm{L}^{-1}$. Strain PHS-1 grew over a salinity range of $8-98 \mathrm{~g} \cdot \mathrm{L}^{-1}$, with the optimum growth rate at $33 \mathrm{~g} \cdot \mathrm{L}^{-1}$. BSL-9 grew optimally at a salinity of $48 \mathrm{~g} \cdot \mathrm{L}^{-1}$. 

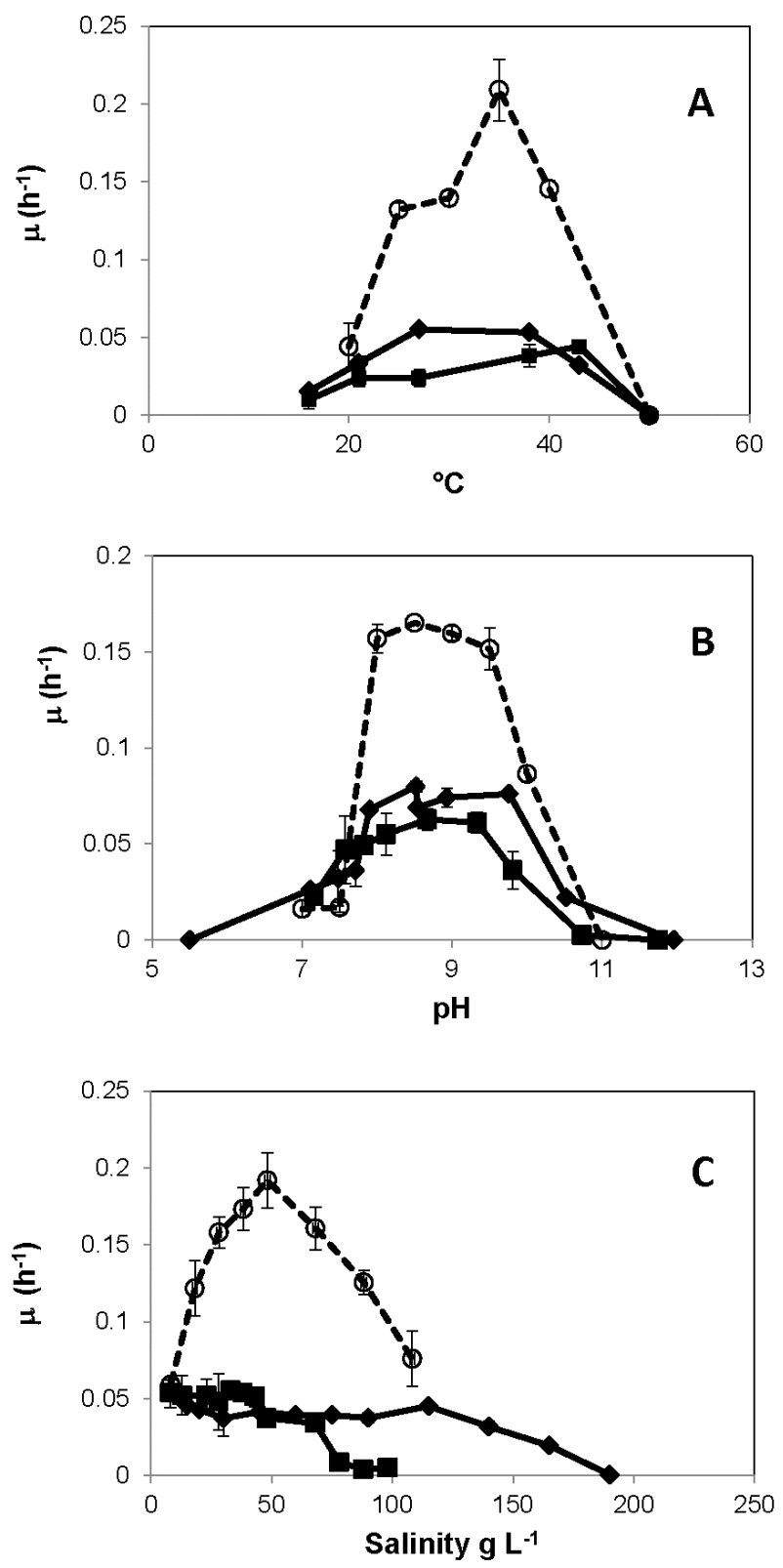

Figure 3. Optimal growth parameters for $(\mathbf{\square})$ strain PHS-1, $(\checkmark)$ strain MLW-1 and $(\bigcirc)$ strain BSL-9: (A) temperature; (B) $\mathrm{pH}$; and (C) salinity. Symbols represent the mean of three cultures, and bars indicate \pm SD.

\subsection{Morphological Characteristics of the Isolates}

Strain PHS-1 is a gram-negative, motile rod (dimensions: $1.5-2.5 \times 0.5-0.7 \mu \mathrm{m}$ ). Thin sections of PHS-1 cells displayed lamellar intracytoplasmic membranes (ICMs) (Figure 4A). Strain MLW-1 is a bean-shaped, gram-negative motile rod (dimensions: 1.0-2.2 $\times 0.5-0.75 \mu \mathrm{m}$ ). Thin sections of MLW-1 and BSL-9 cells revealed lamellar ICMs (Figure 4B-D). The cell suspensions of all three strains grown in the light were a deep red color. Absorption spectra of whole cells showed maxima at 800 and $850 \mathrm{~nm}$, indicative of bacteriochlorophyll $a$ (Figure 5). 


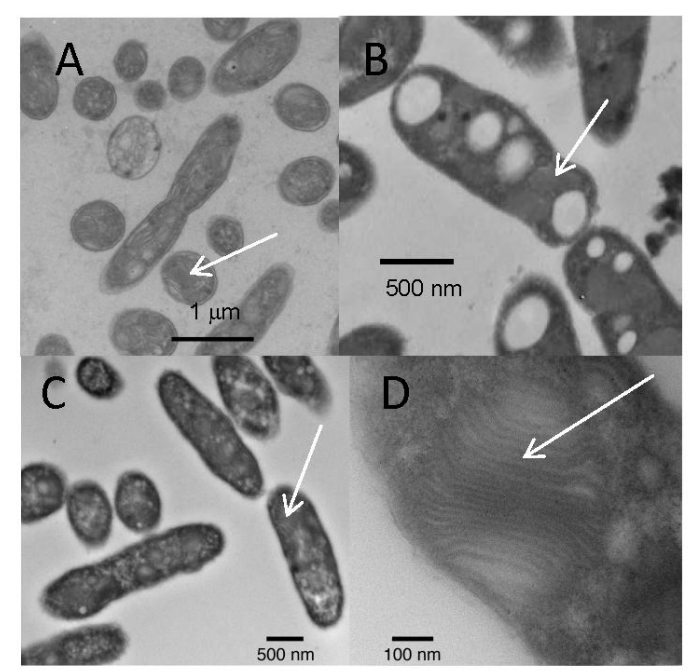

Figure 4. Thin sections of (A) strain PHS-1; (B) strain MLW-1; (C) strain BSL-9; and (D) strain BSL-9, lamellar intracytoplasmic membranes shown in detail. Arrows indicate locations of lamellar structures.

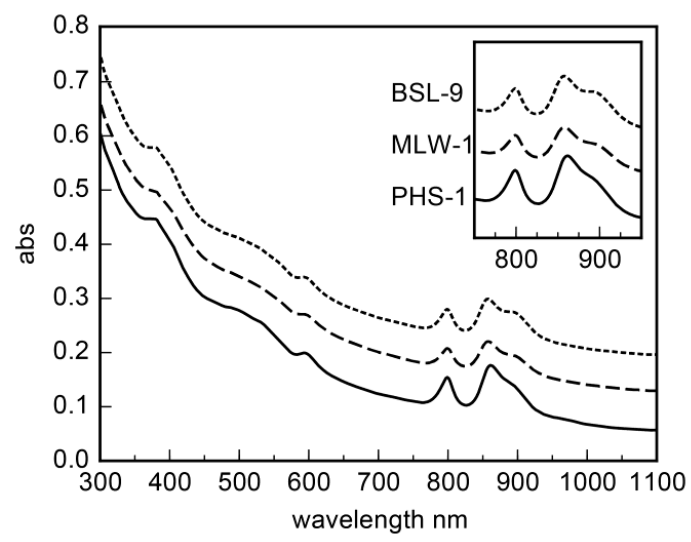

Figure 5. Absorption spectra of intact cells of strains BSL-9, MLW-1, and PHS-1, showing characteristic absorption peaks at $800 \mathrm{~nm}$ and $850 \mathrm{~nm}$.

\subsection{Phylogenetic Analysis}

The results of the phylogenetic analysis indicated that strains PHS-1, MLW-1, and BSL-9 belong to the genus Ectothiorhodospira (Figure 6). BLAST analysis indicated the closest relative to MLW-1 was Ectothiorhodospira "Borgoria Red" strain RM1 (AF 384206) with a 99\% sequence identity. The closest relative to BSL-9 was also strain RM1, but with a $98 \%$ sequence identity. The closest relative to PHS-1 was Ectothiorhodospira shaposhnikovii strain DSM 2111 with a 99\% sequence identity. These results were based on percent coverage, as other strains had as high a percentage sequence identity. The phylogenetic tree revealed that Ectothiorhodospira sp. strain ML Ecto, also from Mono Lake, aligned with MLW-1. The overall ambiguity in the branching and low boot-strap values are due to the very high sequence identity within the Ectothiorhodospira, which extends not only to strains of the same species from different geographic areas, but also for entirely different species (e.g., Ect. haloalkaliphila, Ect. magna, Ect. marina, and Ect. shaposhnikovii). DNA-DNA hybridization results indicated that PHS-1 belongs to the same species as Ectothiorhodospira shaposhnikovii DSM 2111 (81.1\% sequence similarity) and is a separate species from Ectothiorhodospira shaposhnikovii DSM $243^{\mathrm{T}}$ ( $58.1 \%$ sequence similarity). 


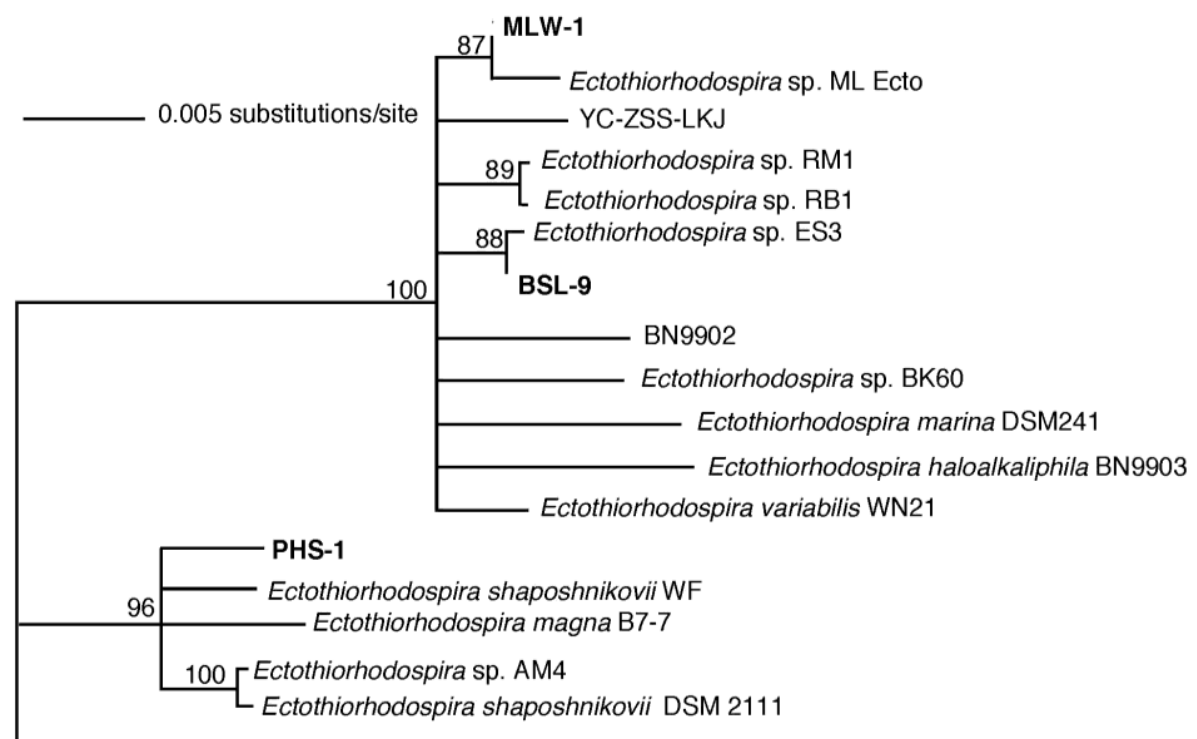

Thiorhodospira sibirica B8-1

Figure 6. Phylogenetic tree base on 16S rRNA gene sequences for MLW-1, BSL-9 and PHS-1. BLAST searches using NCBI were done individually for MLW-1, BSL-9 and PHS-1 to find the closest phylogenetic relatives. Additional 16S rRNA gene sequences of closely related Ectothiorhodospira strains were obtained from NCBI. The sequences were aligned using CLUSTAL X and a neighbor joining tree was constructed using PAUP* 4.0b [22]. Accession numbers: Ectothiorhodospira "Borgoria Red" strain RM1 (AF384206), Ectothiorhodospira “Borgoria Red” strain RB1 (AF384207), YC-ZSS-LKJ151 (KP174461), Ectothiorhodospira sp. ML Ecto (EU341299), Ectothiorhodospira sp. strain ES3 (EU908046), BN9902 (X93475), Ectothiorhodospira sp. strain BK60 (KP681556), Ectothiorhodospira marina DSM 241 (NR044898), Ectothiorhodospira haloalkaliphila strain BN9903 (NR044900), Ectothiorhodospira variabilis strain WN21 (AM943125), Ectothiorhodospira shaposhnikovii strain WF (KJ586501), Ectothiorhodospira magna strain B7-7 (NR108987), Ectothiorhodospira sp. strain AM4 (EU252492), Ectothiorhodospira shaposhnikovii strain DSM 2111 (FR733667), Thiorhodospira sibirica strain B8-1 (HQ877088).

\subsection{Analysis of the Anaerobic Arsenite Oxidase Gene arxA}

Molecular detection of genes encoding arsenite oxidases (aio $A$ and $\operatorname{ar} x A$ ) by PCR indicated that PHS-1, MLW-1, and BSL-9 lacked aioA but contained arxA (Figure S3). Halorhodospira halophila, Ectothiorhodospira shaposhnikovii DSM 243 ${ }^{\mathrm{T}}$, and Ectothiorhodospira shaposhnikovii DSM 2111 contained $\operatorname{arx} A$ but lacked aioA. No aio genes were detected within the genome sequences for PHS-1 and BSL-9 [27]. For PHS-1 and BSL-9 the complete arxA genes were retrieved from their genome sequences and a partial arxA sequence for MLW-1 and for Halorhodospira halophila was determined from a PCR amplicon generated using primers from the BSL-9 arxA gene. Pairwise analysis among these $\operatorname{ar} x A$ sequences indicated that PHS-1 ar $x A$ was the most divergent, with $70 \%$ and $73 \%$ sequence identity scores relative to BSL-9 and MLW-1, respectively. The arxA for the two strains was highly homologous as they share 98\% DNA sequence identity (Figure 7). The lack of aio genes and the presence of arx gene clusters in PHS-1, MLW-1, and BSL-9 suggest that the mechanism for photosynthetic arsenite oxidation is likely associated with arx in these organisms. 


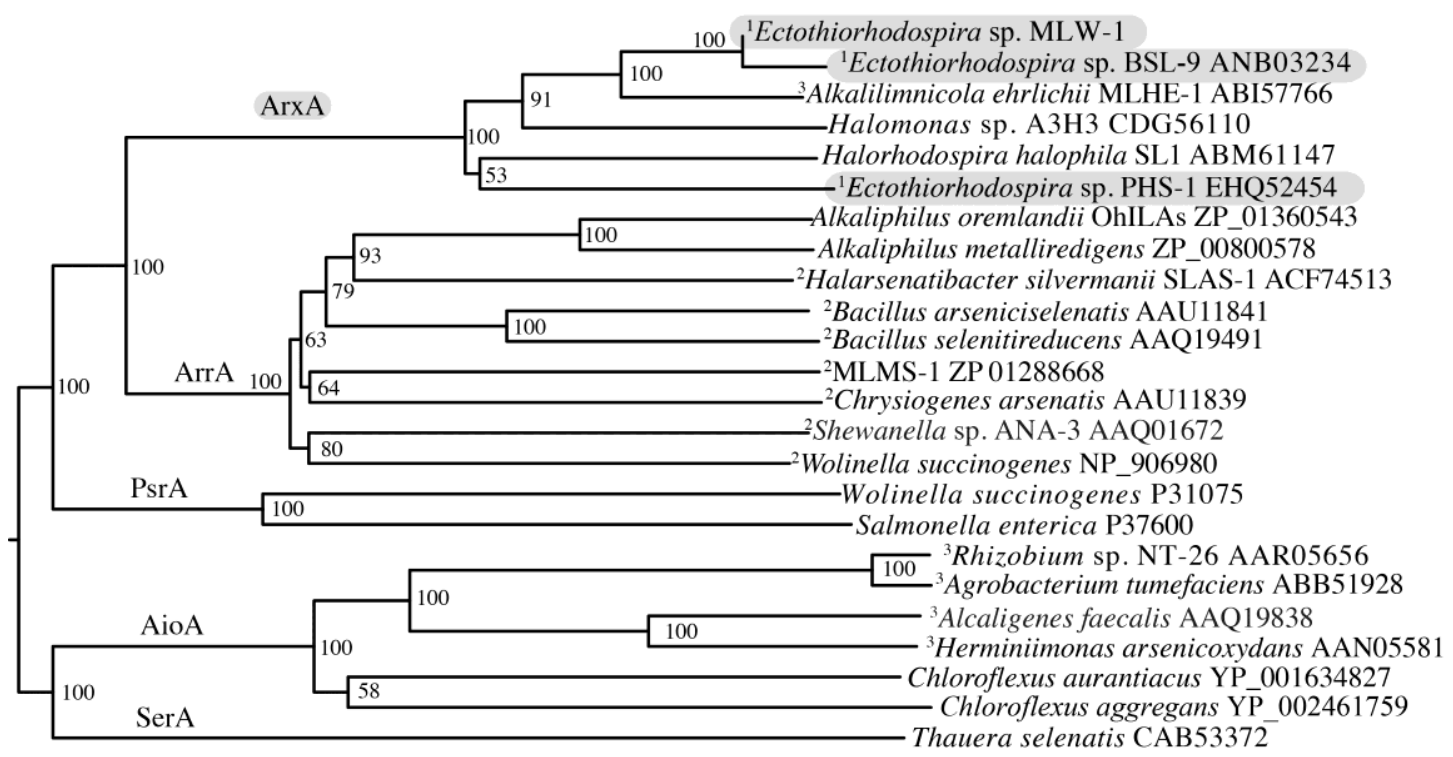

0.05

Figure 7. Phylogenetic analysis of ArxA-type arsenite oxidase, and other clades of DMSO reductase family molybdenum enzymes. The Genbank accession numbers are noted at the end of each OTU. KALIGN (http://www.ebi.ac.uk/Tools/msa/kalign/) was used for the multisequence alignment. The phylogenetic inference was done using PAUP using the distance criterion and neighbor joining for tree searching. Gaps within multi-sequence alignment were included, which resulted in 1099 possible positions for constructing the final tree. The tree was rooted on selenate reductase, SerA. Superscripts 1 , 2 , and 3 indicate that the organism oxidizes arsenite coupled to photosynthesis, respires arsenate, or oxidizes arsenite chemoautotrophically, respectively. Grey highlights the new species described in the current manuscript.

\section{Discussion}

The overall goals of this work were to demonstrate As(III)-linked photosynthetic growth in new strains of Ectothiorhodospira taken from As-rich soda lakes, and to determine whether they all shared a similar genetic mechanism responsible for this oxidation (i.e., $\operatorname{arx} A$ ). Clear evidence for robust As(III)-dependent anaerobic phototrophic growth was observed in strains MLW-1 and BSL-9 (Figure 1), as was previously reported for strain PHS-1 [4], as well as an Ectothiorhodospira-dominated enrichment culture established from Mono Lake water [3]. The three type culture strains were also able to oxidize As(III) (Figure 2A,C,E), but growth only occurred for Ect. shaposhikovii DSM $243^{\mathrm{T}}$ and Ect. shaposhnikovii DSM 2111 in the presence of sulfide, with As(III) providing a marginal growth enhancement for the former but not the latter microorganism (Figure 2B,D). H. halophila's growth was even more complicated to interpret in that we used a carbon source taken from the literature (succinate) as well as sulfide to achieve growth. When As(III) was provided as an electron donor in addition to sulfide and succinate, a modest stimulation of growth occurred (Figure 2F). Under reducing conditions, sulfide reacts with arsenite to form thioarsenates [31], thus it may be that these strains are growing on thioarsenates rather than As(III) or sulfide [32], but we did not pursue this question as it was beyond the scope of the investigation. The capacity to link electrons scavenged from As(III) oxidation to anoxygenic phototrophic growth appears to be a common feature amongst these haloalkaliphilic autotrophs. However, the ability to achieve this feat solely with As(III) as the electron donor seems to require the isolation of new strains that have been deliberately selected for this capacity as part and parcel of the cultivation process.

The currently described genetic pathways for arsenite oxidation include aio and arx. For the latter, it was first shown previously that As(III)-dependent growth in the chemoautotroph Alkalilimnicola 
ehrlichii required $\operatorname{ar} x A$ [12]. For photosynthetic arsenite oxidation, genome sequencing analysis and gene expression observations of PHS-1 hinted at a possible arx-dependent pathway [14]. However, this was first confirmed in BSL-9 by demonstrating disruptive mutants of arxA in strain BSL-9 were unable to oxidize As(III) or achieve phototrophic growth with As(III) [33]. Closer inspection of the PHS-1 genome revealed an arx gene cluster $(\operatorname{ar} x B 2 A B C)$ that closely aligned with the arx gene cluster of BSL-9 and MLHE-1 [14,33]. Moreover, MLHE-1, BSL-9, and PHS-1 lacked homologs to any of the currently known aio sequences. In light of these genome sequence observations and genetic studies with BSL-9 and MLHE-1, our PCR detection results suggest that PHS-1 and MLW-1 may also use the arx pathway for As(III) oxidation. Further genetic work is needed to test this hypothesis. For the other strains, our PCR results led to the detection of arxA in H. halophila, Ect. shaposhnikovii DSM 243 ${ }^{T}$, and Ect. shaposhnikovii DSM 2111 but not aioA genes (Figure S3), also suggestive of an arx-dependent pathway for arsenite oxidation, as was previously demonstrated for BSL-9 and MLHE-1. For H. halophila, its genome sequence also contains an arx-like gene cluster and its ArxA-like sequence falls within the ArxA clade (Figure 7). None of these three strains represent new species based on their 16S rRNA gene sequence similarities to the established Ectothiorhodospira strain RM1 (Figure 6) and, in the case of PHS-1, its close proximity to Ect. shaposhnikovii DSM 2111 rather than Ect. shaposhnikovii DSM $243^{T}$, as established by DNA-DNA hybridization. Indeed, for the most part their growth-supporting substrate affinities for electron donors have far more compounds in common than not, including, in addition to arsenite, sulfide, thiosulfate, acetate, lactate, propionate, succinate, malate, and pyruvate (Table 1).

Physiological differences between the three strains are, with the exception of salinity, relatively minor and generally reflect the locales from which they were isolated. Strain PHS-1 came from a biofilm in a hot spring located on Paoha Island [4]. The spring water temperature was $\sim 45^{\circ} \mathrm{C}$ and, given a roughly 50-50 mix with perched freshwater, had a salinity and arsenic content about half that of Mono Lake water, while strain MLW-1 was taken from the shoreline of the lake and exposed to its full salinity. Hence, strain PHS-1 shows a slightly higher temperature preference (Figure 3A), a similar $\mathrm{pH}$ range (Figure 3B), but a markedly lower salinity tolerance (Figure 3C). All three strains were clearly alkaliphilic.

The arx genes have been elucidated relatively recently [11] when compared with the better studied aio genes that are commonly linked to aerobic As(III) oxidation [34]. Our work now broadens the occurrence of $a r x$ genes within photosynthetic bacteria isolated from three different environments located in two arsenic-rich soda lakes (Mono Lake and Big Soda Lake). They now include Ectothiorhodospira strain PHS-1, Ectothiorhodospira RM1 strain MLW-1, and Ectothiorhodospira RM1 strain BSL-9. The chemoautotroph A. ehrlichii has already been shown to possess the arx gene [12]. Hamamura et al. [15] reported the presence of $\operatorname{arx} A$ homologs in amplicons from sediment-extracted DNA from a Tukh Lake, a soda lake located in Mongolia. They also isolated a chemoorganotrophic nitrate-respiring bacterium, Halomonas strain ANAO-440, which possesses arxA and oxidized As(III) to $\mathrm{As}(\mathrm{V})$ during heterotrophic growth. A recent transcriptomic study documented in situ expression of the $\operatorname{arxA}$ gene in a photosynthetic biofilm on Paoha Island, Mono Lake [33], the site of earlier investigations of As(III)-linked anoxygenic photosynthesis [4,10]. A broad meta-transcriptomic study of the entire water column in Mono Lake found that expression of arx $A$ genes was abundant at several depths, especially at and below the $15 \mathrm{~m}$ oxycline, while expression of aio $A$ was confined to only one depth $(10 \mathrm{~m})$ in the oxic epilimnion. Moreover, transcripts of $\operatorname{ar} x A$ were far more abundant overall than those of aio $A[35,36]$. Taken together, these two studies underscore the importance of expression of ArxA as a mechanism of As(III) oxidation in Mono Lake's hot spring and water column environments. It remains to be seen whether $\operatorname{arx} A$ genes occur and are expressed in other types of As-rich environments (e.g., contaminated groundwater; acid mine drainages; neutral/acidic $\mathrm{pH}$ hot springs) besides soda lakes.

Supplementary Materials: The following are available online at http://www.mdpi.com/2075-1729/7/1/1/s1.

Acknowledgments: This work was supported by the USGS National Research Program (Ronald S. Oremland and Shelley Hoeft McCann) and NASA Exobiology \#13-EXO13-001 (Ronald S. Oremland). 
Author Contributions: Shelley Hoeft McCann, Ronald S. Oremland, and Chad W. Saltikov conceived and designed the experiments. Shelley Hoeft McCann, Alison Boren, Jaime Hernandez-Maldonado, Brendon Stoneburner, and John F. Stolz performed research and analyzed results. Chad W. Saltikov and John F. Stolz assisted in writing the paper. Shelley Hoeft McCann and Ronald S. Oremland wrote the paper.

Conflicts of Interest: The authors declare no conflict of interest.

\section{References}

1. Imhoff, J.F.; Süling, J. The phylogenetic relationship among Ectothiorhodospiraceae: A re-evalution of their taxonomy on the basis of 16S rDNA analyses. Arch. Microbiol. 1996, 165, 106-113. [CrossRef] [PubMed]

2. Imhoff, J.F. The Family Ectothiorhodospiraceae. In The Prokaryotes: A Handbook on the Biology of Bacteria, 3rd ed.; Dworkin, M., Falkow, S., Rosenberg, E., Schleifer, K.H., Stackebrandt, E., Eds.; Springer: New York, NY, USA, 2006; Volume 6, pp. 874-886.

3. Budinoff, C.R.; Hollibaugh, J.T. Arsenite-dependent photoautotrophy by an Ectothiorhodospira-dominated consortium. ISME J. 2008, 2, 340-343. [CrossRef] [PubMed]

4. Kulp, T.R.; Hoeft, S.E.; Asao, M.; Madigan, M.T.; Hollibaugh, J.T.; Fisher, J.C.; Stolz, J.F.; Culbertson, C.W.; Miller, L.G.; Oremland, R.S. Arsenic (III) fuels anoxygenic photosynthesis in hot spring biofilms from Mono Lake, California. Science 2008, 321, 967-970. [CrossRef] [PubMed]

5. Oremland, R.S. A random biogeochemical walk into three soda lakes of the western USA: With an introduction to a few of their microbial denizens. In Polyextremophiles, Life under Multiple Forms of Stress; Seckbach, J., Oren, A., Stan-Lotter, H., Eds.; Springer: New York, NY, USA, 2013; pp. 180-199.

6. Oremland, R.S.; Stolz, J.F.; Hollibaugh, J.T. The microbial arsenic cycle in Mono Lake, California. FEMS Microbiol. Ecol. 2004, 48, 15-27. [CrossRef] [PubMed]

7. Oremland, R.S.; Dowdle, P.R.; Hoeft, S.; Sharp, J.O.; Schaefer, J.K.; Miller, L.G.; Switzer Blum, J.; Smith, R.L.; Bloom, N.S.; Wallschlaeger, D. Bacterial dissimilatory reduction of arsenate and sulfate in meromictic Mono Lake, California. Geochim. Cosmochim. Acta 2000, 64, 3073-3084. [CrossRef]

8. Hoeft, S.E.; Kulp, T.R.; Stolz, J.F.; Hollibaugh, J.T.; Oremland, R.S. Dissimilatory arsenate reduction with sulfide as electron donor: Experiments with Mono Lake water and isolation of strain MLMS-1, a chemoautotrophic arsenate respirer. Appl. Environ. Microbiol. 2004, 70, 2741-2747. [CrossRef] [PubMed]

9. Hoeft, S.E.; Lucas, F.; Hollibaugh, J.T.; Oremland, R.S. Characterization of bacterial arsenate reduction in the anoxic bottom waters of Mono Lake, California. Geomicrobiology 2002, 19, 1-19.

10. Hoeft, S.E.; Blum, J.S.; Stolz, J.F.; Tabita, F.R.; Witte, B.; King, G.M.; Santini, J.M.; Oremland, R.S. Alkalilimnicola ehrlichii sp. nov., a novel, arsenite-oxidizing haloalkaliphilic gammaproteobacterium capable of chemoautotrophic or heterotrophic growth with nitrate or oxygen as the electron acceptor. Int. J. Syst. Evol. Microbiol. 2007, 57, 504-512. [CrossRef] [PubMed]

11. Richey, C.; Chovanec, P.; Hoeft, S.E.; Oremland, R.S.; Basu, P.; Stolz, J.F. Respiratory arsenate reductase as a bidirectional enzyme. Biochem. Biophys. Res. Commun. 2009, 382, 298-302. [CrossRef] [PubMed]

12. Zargar, K.; Hoeft, S.E.; Oremland, R.S.; Saltikov, C.S. Identification of a novel arsenite oxidase gene, $\operatorname{arx} A$, in the haloalkaliphilic, arsenite-oxidizing bacterium Alkalilimnicola ehrlichii strain MLHE-1. J. Bacteriol. 2010, 192, 3755-3762. [CrossRef] [PubMed]

13. Hoeft, S.E.; Kulp, T.R.; Han, S.; Lanoil, B.; Oremland, R.S. Coupled arsenotrophy in a hot spring photosynthetic biofilm at Mono Lake, California. Appl. Environ. Microbiol. 2010, 76, 4633-4639. [CrossRef] [PubMed]

14. Zargar, K.; Conrad, A.; Bernick, D.L.; Lowe, T.M.; Stolc, V.; Hoeft, S.E.; Oremland, R.S.; Stolz, J.F.; Saltikov, C.W. ArxA, a new clade of arsenite oxidase within the DMSO reductase family of molybdenum oxidoreductases. Environ. Microbiol. 2012, 14, 1635-1645. [CrossRef] [PubMed]

15. Hamamura, N.; Itai, T.; Liu, Y.; Reysenbach, A.-L.; Damdinsuren, N.; Inskeep, W.P. Identification of anaerobic arsenite-oxidizing and arsenate-reducing bacteria associated with an alkaline saline lake in Khovsgol, Mongolia. Environ. Microbiol. Rep. 2014, 6, 476-482. [CrossRef] [PubMed]

16. Widdel, F.; Koring, G.W.; Mayer, F. Studies on the dissimiliatory sulfate-reducing bacteria that decompose fatty acids. 3. Characterization of the filamentous gliding Desulfonema limicola, gen. nov. sp. nov., and Desulfonema magnum, sp. nov. Arch. Microbiol. 1983, 134, 286-294. [CrossRef] 
17. Oremland, R.S.; Blum, J.S.; Culbertson, C.W.; Visscher, P.T.; Miller, L.G.; Dowdle, P.; Strohmaier, F.E. Isolation, growth, and metabolism of an obligately anaerobic, selenite-respiring bacterium strain SES-3. Appl. Environ. Microbiol. 1994, 60, 3011-3019. [PubMed]

18. Hermann, M.; Noll, K.M.; Wolfe, R.S. Improved agar bottle plate for isolation of methanogens or other anaerobes in a defined gas atmosphere. Appl. Environ. Microbiol. 1986, 51, 1124-1126. [PubMed]

19. Widdel, F.; Pfennig, N. Studies on dissimilatory sulfate-reducing bacteria that decompose fatty acids. Arch. Microbiol. 1981, 129, 395-400. [CrossRef] [PubMed]

20. Kostka, J.; Nealson, K. Isolation, cultivation, and characterization of iron- and manganese-reducing bacteria. In Techniques in Microbial Ecology; Burlage, R.S., Atlas, R., Stahl, D., Geesey, G., Sayler, G., Eds.; Oxford University Press: Oxford, UK, 1998; pp. 58-78.

21. Raymond, J.C.; Sistrom, W.R. Ectothiorhodospira halophila: A new species of the genus Ectothiorhodospira. Arch. Mikrobiol. 1969, 69, 121-126. [CrossRef] [PubMed]

22. Swofford, D.L. PAUP*. Phylogenetic Analysis Using Parsimony (*and Other Methods), Version 4; Sinauer Associates: Sunderland, MA, USA, 2003.

23. Cashion, P.; Hodler-Franklin, M.A.; McCully, J.; Franklin, M. A rapid method for base ratio determination of bacterial DNA. Anal. Biochem. 1977, 81, 461-466. [CrossRef]

24. De Ley, J.; Cattoir, H.; Reynaerts, A. The quantitative measurement of DNA hybridization from renaturation rates. Eur. J. Biochem. 1970, 12, 133-142. [CrossRef] [PubMed]

25. Huss, V.A.R.; Festl, H.; Schleifer, K.H. Studies on the spectrophotometric determination of DNA hybridization from renaturation rates. Syst. Appl. Microbiol. 1983, 4, 184-192. [CrossRef]

26. Sultana, M.; Vogler, S.; Zargar, K.; Schmidt, A.C.; Saltikov, C.; Seifert, J.; Schlömann, M. New clusters of arsenite oxidase and unusual bacterial groups in enrichments from arsenic-contaminated soil. Arch. Microbiol. 2012, 194, 623-635. [CrossRef] [PubMed]

27. Hernandez-Maldonado, J.; Stoneburner, B.; Boren, A.; Miller, L.; Rosen, M.; Oremland, R.S.; Saltikov, C.W. Genome sequence of the photoarsenotrophic bacterium, Ectothiorhodospira str. sp. BSL-9, isolated from a saline alkaline arsenic rich extreme environment. Genome Announc. 2016, 4. [CrossRef] [PubMed]

28. Smith, R.L.; Strohmaier, F.S.; Oremland, R.S. Isolation of anaerobic oxalate degrading bacteria from freshwater lake sediments. Arch. Microbiol. 1985, 14, 8-13. [CrossRef]

29. Switzer Blum, J.; Burns Bindi, A.; Buzzelli, J.; Stolz, J.; Oremland, R.S. Bacillus arsenicoselenatis sp. nov., and Bacillus selenitireducens sp. nov.: Two haloalkaliphiles from Mono Lake, California which respire oxyanions of selenium and arsenic. Arch. Microbiol. 1998, 171, 19-30. [CrossRef] [PubMed]

30. Cline, J.D. Spectrophotometric determination of hydrogen sulfide in natural waters. Limnol. Oceanogr. 1969, 14, 454-459. [CrossRef]

31. Stauder, S.; Raue, B.; Sacher, F. Thioarsenates in sulfidic waters. Environ. Sci. Technol. 2005, 39, 5933-5939. [CrossRef] [PubMed]

32. Edwardson, C.F.; Planer-Friedrich, B.; Hollibaugh, J.T. Transformation of monothioarsenate by haloalkaliphilic, anoxygenic photosynthetic purple sulfur bacteria. FEMS Microbiol. Ecol. 2014, 90, 858-868. [CrossRef] [PubMed]

33. Hernandez-Maldonado, J.; Sanchez-Sedillo, B.; Stoneburner, B.; Boren, A.; Miller, L.G.; Hoeft McCann, S.; Rosen, M.; Oremland, R.S.; Saltikov, C.W. The genetic basis of anoxygenic photosynthetic arsenite oxidation. Environ. Microbiol. 2016. [CrossRef] [PubMed]

34. Andres, J.; Bertin, P.N. The microbial genomics of arsenic. FEMS Microbiol. Rev. 2016, 40, 299-322. [CrossRef] [PubMed]

35. Edwardson, C.F. Microbially Mediated Transformation of Arsenic and Sulfur Compounds in Mono Lake, California, USA. Ph.D. Thesis, University of Georgia, Athens, GA, USA, 2015.

36. Edwardson, C.F.; Hollibaugh, J.T. Metatranscriptomic analysis of the prokaryotic community active in sulfur and arsenic cycling in alkaline, hypersaline Mono Lake, California. ISME J. 2016. in revision.

(C) 2016 by the authors; licensee MDPI, Basel, Switzerland. This article is an open access article distributed under the terms and conditions of the Creative Commons Attribution (CC-BY) license (http://creativecommons.org/licenses/by/4.0/). 